\title{
Clinical Waste Management Scenario of Private Health Care Establishment in Rajshahi City
}

\author{
Md Razibur Rahman, Abdul Hamid and Md Shariful Islam* \\ Department of civil Engineering, RUET, Bangladesh \\ *Corresponding author: Md Shariful Islam, Department of civil Engineering, RUET, Bangladesh
}

\begin{abstract}
The increasing number of clinics and hospitals in Bangladesh has been resulting in the increased amount of waste generation. Clinical waste contains toxic chemicals and hazardous materials from several diagnosis and treatment processes. The improper disposal of clinical waste in the country poses a high health risk to humans as well as the environment.

The study of clinical waste management systems was performed to understand the various handling and disposal procedures in different clinics and diagnostics center in Rajshahi city, the knowledge and awareness of individuals involved in medical waste generation, handling and disposal, and the potential impacts of the waste stream on both human health and the natural environment. The purpose of the study is to provide direction for further study. Data were collected by field investigation and interview in the selected clinics and diagnostics center. It was found that a variety of methods were used by the medical facilities to dispose their wastes including burning, burial, entombing, selling, dumping, and removal by municipal bins. The waste disposal practice was found to be quite unsafe, and both clinical and non-clinical wastes were found to be thrown together. There was insufficient awareness of the magnitude of the medical wastes issue by concerned individuals at different levels from director or divisional head to tokai (waste pickers). This study aims at bringing safety, health and environment together as a basis for prioritizing national programmed, through collection of data on types, quantities, sources handling procedures and basic understanding by those in charge. In addition, it is also aimed at proposing ways of reducing levels of contact with hazardous health-care waste.

The improvement of waste management in clinics and hospitals is essential to minimize the spread of infectious diseases. The study was conducted at different 19 clinics and diagnostic centers at Rajshahi city in Bangladesh to quantify amount of clinical waste generated from the medical services; determine physical composition of; find out the correlation of waste quantity with relevant factors; identify problems and develop future guideline regarding waste management.
\end{abstract}

Keywords: Hazardous materials; Medical wastes; Health risk; Infectious diseases

\section{Introduction}

A hospital is a service-oriented residential establishment that provides medical care facilities comprising of observational, diagnostic, therapeutic and rehabilitative services for persons suffering from or suspected to be suffering from many kind of diseases or injury. The basic concept of waste management in a hospital do not differ basically from that in hotels, schools and catering establishments since certain areas of the hospital render the same type of basic services. But some wastes generated in a hospital are too hazardous to be treated negligently, and any carelessness in the management of these wastes in a hospital tends to spread infection and contaminate in the entire living environment prevailing in a hospital. The delay in the recovery and overburden of weak patients, endanger the patients survival and may also generate health hazards to those persons who work in the hospital environment.

Over the years, the world has witnessed the rapid population growth in different patterns and extra-ordinary waste generation. In many developed and developing countries, collection, transportation, treatment and disposal of waste are the major challenges for government, organizations and other institutions. Different types of solid wastes depending on the generation resource can be classified into household waste or municipal waste, industrial waste as hazardous waste and biomedical waste. 
Biomedical waste or clinical waste is classified as one of the most dangerous wastes in the world. Clinical waste refers to any waste that is generated during medical activities such as diagnosis, monitoring, and treatment of human beings or animals. It includes viruses and bacteria that potentially cause diseases which are produced by hospitals, clinics, doctor's offices and other types of healthcare institutions.

In recent years, concern over clinical waste has increased throughout the world. Improper management of clinical waste poses a public health risk. Therefore, appropriate Clinical Waste Management is a crucial issue for maintaining human and public health. The Clinical waste management practices cover all processes from the point of identification the wastes, to the place it is disposed in an incinerator. Initial handling, collecting, transporting, disposing and monitoring of waste materials are collectively called waste management. The primary objectives of waste management are reducing the amount and hazards of waste. Reusing the waste through the provision of secondary raw materials and use of the waste as energy resource are other objectives of waste management.

Clinical waste has been considered as one of the major health and environmental concern in Bangladesh over the last three decades. Poor management, lack of handling knowledge and unscientific disposal of various health care wastes pose serious direct and indirect public health threats to health-care personnel, nurses, technicians, waste workers, hospital visitors, patients, surrounding communities and hence, the environment [1,2]. Clinical waste, due to its content of hazardous substances such as heavy metals, chemical solvents and preservatives, poses serious threats to environmental health such as, air pollution through release of toxic pollutants (e.g. dioxin), water pollution through surface run off and infiltration of leachate into water bodies and underground aquifer.

Clinical waste contains highly toxic metals, toxic chemicals, pathogenic viruses and bacteria, which can lead to pathological dysfunction of the human body. Clinical waste presents a high risk to doctors, nurses, technicians, sweepers, hospital visitors and patients due to arbitrary management.

It is observed that the solid clinical wastes are being disposed-off in the City Corporation's collection bins in and around the hospital premises. The waste is then collected by City Corporation's vehicles and then transported to the open municipal dumping sites. Simply disposing it into dustbins, drains, and canals or finally dumping it to the outskirts of the city poses a serious public health hazard. It is a common observation in Rajshahi City that poor scavengers, women and children collect some of the diagnostic wastes (e.g. syringeneedles, saline bags, blood bags etc.) for reselling despite the deadly health risks. It has long been known that the re-use of syringes can cause the spread of infection such as AIDS and hepatitis [2]. The collection of disposable medical items (particularly syringes), its resale and potential re-use without sterilization could cause a serious disease burden. The safe disposal and subsequent destruction of diagnostic waste is a key step in the reduction of illness or injury through contact with this potentially hazardous material, and in the prevention of environmental contamination [3]. The transmission of blood-borne viruses and respiratory, enteric and soft tissue infections through improper clinical waste disposal is not well described. The management of clinical waste therefore, has been of major concern due to potentially high risks to human health and the environment [4].

\section{Objectives}

The objectives of the study are as follows:

(a) To study the existing situation of clinical waste management in Rajshahi city.

(b) To quantify the amount of solid wastes generated by each health care establishment.

(c) To identify the problems and inadequacies associated with the current situation of the clinical waste management in the Rajshahi city.

\section{Clinical Waste Types and Sources}

Generally, clinical waste is defined as the discarded or unwanted material or garbage or solid waste which is generated from the diagnosis, treatment, or immunization of human beings or animals, in research pertaining thereto, or in the production or testing of biological. These have the potential to cause disease and are a health risk. It is by-product of health care that includes sharps, non-sharps, blood, body parts, chemicals, pharmaceuticals, medical devices and radioactive materials. The Health Care Establishments are one of the major producers of solid wastes which are hazardous in nature. Poor management of clinical wastes exposes heath workers, waste handlers and the community to infections, toxic effects and injuries.

\section{Sources and Types of Clinical Wastes}

Medical wastes are mainly categorized into non-hazardous and hazardous wastes. The non-hazardous waste includes wool, kitchen wastes, etc. that do not pose any special handling problem, hazard to health or the environment and is generated in the patients' ward areas, out-patient-department (OPD), kitchens, offices, etc. [5]. The hazardous waste includes pathological, infectious, sharps and chemical wastes and are normally produced in labor wards, operation theatres, laboratories, etc. [5]. Some definitions of clinical wastes are [5] (Figure 1) (Table 1). 


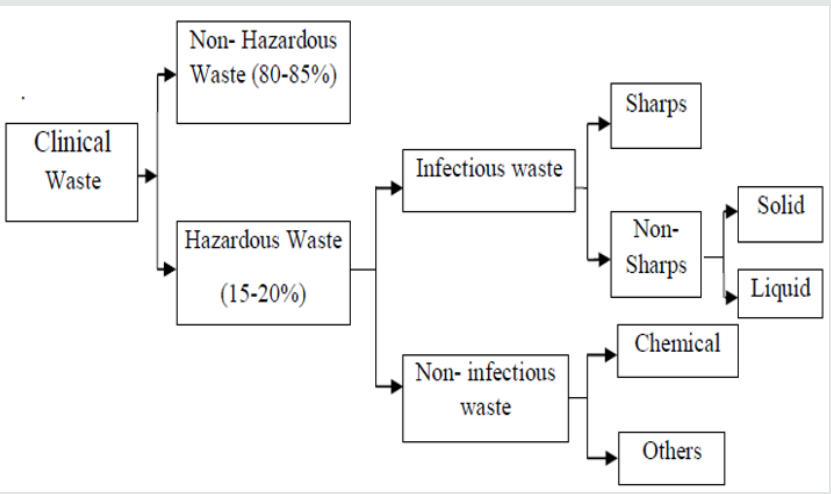

Figure 1: Flow Chart for different types of clinical waste (WHO, 2001).

Table 1: Sources and Types of clinical Wastes (ACHWD, Health Department Victoria, 1988.

\begin{tabular}{|c|c|}
\hline Sources (Clinical Sections) & Type of Wastes \\
\hline Office, Administration & $\begin{array}{c}\text { Paper, Confidential document for } \\
\text { destruction }\end{array}$ \\
\hline Wards & $\begin{array}{l}\text { General, infectious waste, sharps, radio- } \\
\text { active waste, blood, glass ware. }\end{array}$ \\
\hline Pathology /laboratory & $\begin{array}{l}\text { Infectious waste, sharps, radio-active } \\
\text { waste human tissues, solvents }\end{array}$ \\
\hline Radiology & Old firm used developing fluids. \\
\hline Catering & All food waste, packing material. \\
\hline Pharmacy & Obsolete pharmaceuticals, patients. \\
\hline Others & $\begin{array}{c}\text { Garden waste, engineering waste } \\
\text { including solvents. }\end{array}$ \\
\hline
\end{tabular}

\section{Clinical Waste in Environment}

Cheremisinoff \& Shah identified the relation between the waste system and its wastes in the environment as shown in below. This can be relied that clinical wastes are released to the environment by many hospital activities in terms of as air emission, waste water and solid wastes (Figure 2).

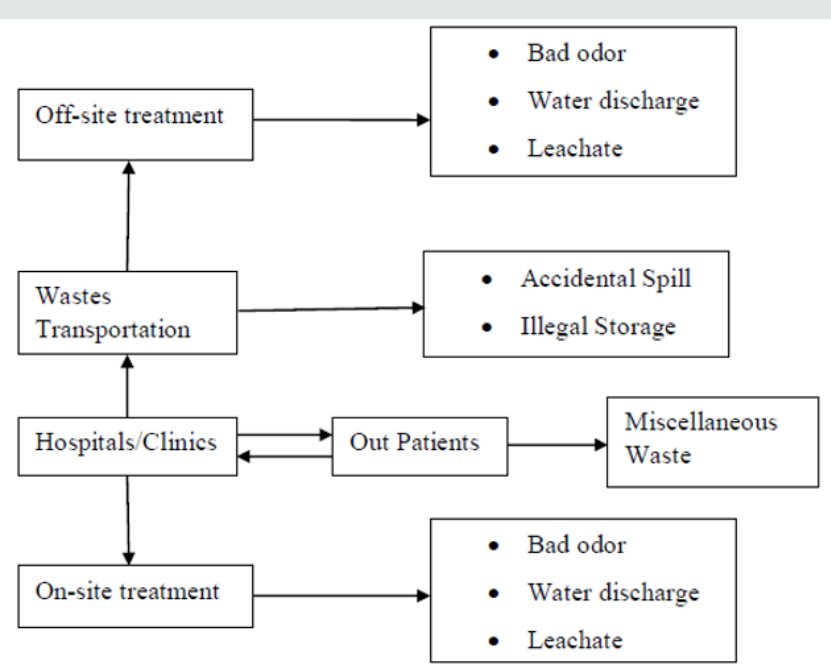

Figure 2: Clinical Wastes in Environment (Cheremisinoff and Shah, 1990).

\section{Public Health Risk}

Meany and Cheremisinoff has defined that infectious diseases occurred as a result of interaction between an infectious agent (pathogen) and a susceptible host. Clinical wastes are a source of pathogen. Interaction between the host and the pathogen may take one of two forms-infections. Infection is the host by the pathogen and is a more common form of diseases introduction [6-10].

There are several modes of diseases transmission from solid wastes but lack of information makes statistical confirmation impossible. In recent years, the USEPA has initiated research in epidemiology and this should promote a greater understanding of the solid waste as shown in Figure 3.

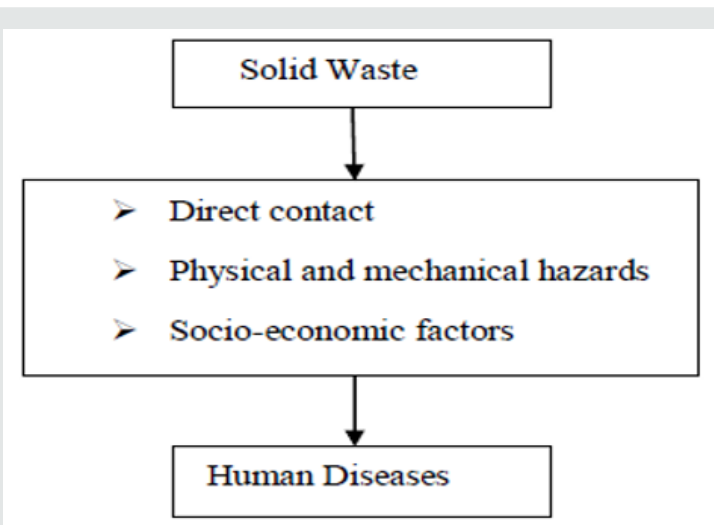

Figure 3: Pathways of Diseases Transmission (Meaney and Cheremisinoff, 1990).

\section{Treatment Method for Clinical Wastes}

There are many treatment methods for the clinical wastes such as Incineration, Autoclaving (stream or heating), Chemical treatment, Microwave radiation and other thermal system and etc. Therefore, clinical wastes should be treated with the suitable treatment method [11-17] (Table 2).

Table 2: Treatment Method for Clinical Wastes.

\begin{tabular}{|cc|}
\hline Hazardous Waste & Treatment Method \\
\hline General waste & $\begin{array}{c}\text { Should join to municipal solid } \\
\text { waste. }\end{array}$ \\
Pathological waste & Incineration \\
Radioactive waste & Incineration \\
Chemical waste & Incineration \\
Sharps & Autoclaving \\
Infectious waste and potentially & \\
infectious wastes & $\begin{array}{c}\text { Autoclaving, Incineration } \\
\text { Pharmaceutical waste } \\
\text { Pressurized containers }\end{array}$ \\
pharmacy for disposed, \\
Incineration
\end{tabular}




\section{Methodology}

The methodology of the study included field observation and field level data collection through inventory, questionnaire survey and interviews with formal and informal ways, a review of related literature etc., to observe the physical composition of clinical waste; and to collect information regarding quantity and quality of diagnostic waste. Data were also collected through both direct observations and interviews with different officials of the studied health care establishments. Waste materials from a hospital as a whole were analyzed (sorting, segregating, and weighting) (Figure 4).

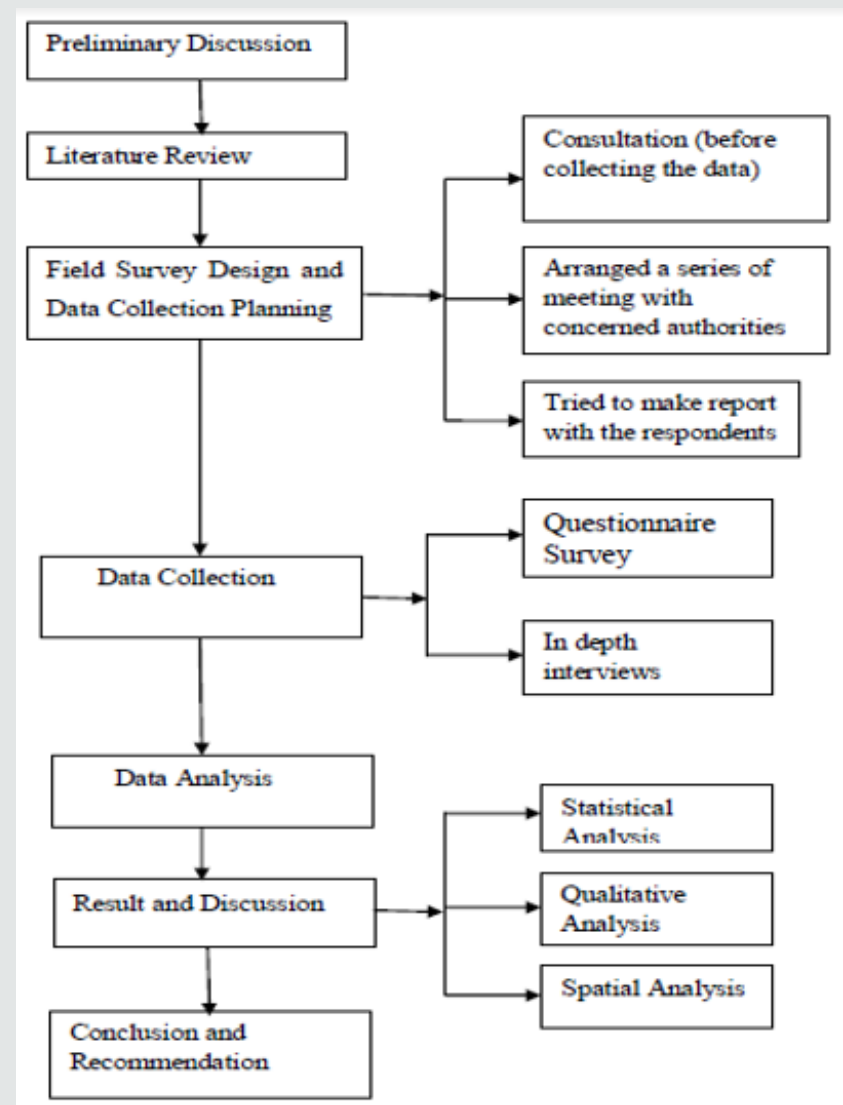

Figure 4: Flow chart for methodological procedure of the project.

\section{Sources and Quantification of Clinical Waste}

Medical wastes are produced by various activities. Different units within a hospitals and clinics such as Medical ward, Operation theatres and surgical ward, Health-care units, Laboratories and Pharmaceutical and Chemical stores would generate different wastes. The amount of waste generated in hospitals depends upon various factors such as the number of beds, types of health services provided, economic, social and cultural status of the patients and the general condition of the area. It was observed that the surveyed Health Care Establishments generated sharp instruments (e.g. needles, syringes, and broken glassware instruments), pathological wastes (e.g. blood, urine bags, cotton-bandages, hands glove), pharmaceutical wastes (e.g. drug shell, saline, glass bottle) and general wastes (e.g. plastics, polythene, papers, food wastes etc) which are considered for segregation of waste. The all Health Care Establishment`s solid wastes are measured in kg/day (Figure 5).

\section{Graphical Representation}
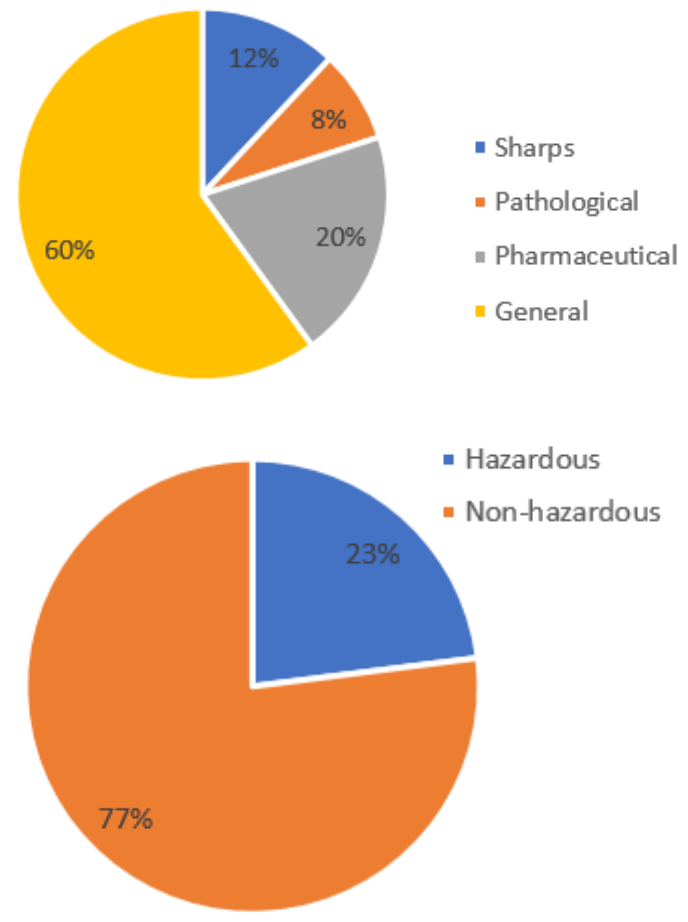

Figure 5: (a) Average Percentage of Clinical Waste in all Health Care Establishments.

(b) Average percentages of Hazardous and Non-hazardous waste.

\section{Results}

\section{Percentage of clinical waste at Islami Bank Hospital}

Islami Bank Hospital is the largest private hospital and very popular having all the facilities (e.g. pathology, radiology and imaging, microbiology, surgery, pharmacology, gynecology and so on). The hospital has 50 beds capacity for resident patients and provides outdoor facilities for about 500 patients daily.

Total amount of waste generated is $39.083 \mathrm{~kg} /$ day (average) on which hazardous waste is $10.7 \mathrm{~kg} /$ day. The rate of waste generation is $0.071 \mathrm{~kg} /$ patient/day. Most of the hazardous wastes are surgical wastes. In this hospital it was found that the percentage amount of general waste generation is $54 \%$, sharp waste is $14 \%$, pathological waste is $9 \%$ and the pharmaceutical waste is $23 \%$ which is shown in below (Figure 6). 


\section{Graphical representation}

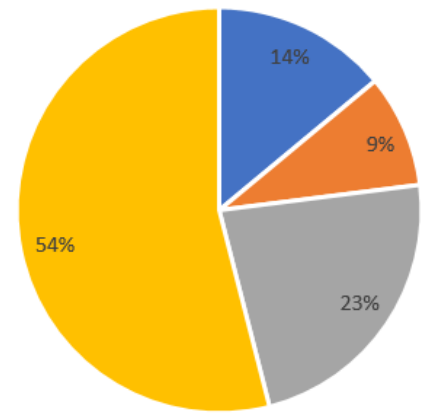

Figure 6: Percentage of clinical Waste at Islami Bank Hospital.

\section{Percentage of clinical Waste at Rajshahi Royal Hospital}

Rajshahi Royal Hospital is another popular private hospital in Rajshahi city. The hospital has 30 beds capacity for resident patients and provides outdoor facilities for about 150 patients daily. In this hospital at first total wastes were segregated first and then different types were weighted. Total amount of waste generated is $13.09 \mathrm{~kg} /$ day (average) on which hazardous waste is $2.667 \mathrm{~kg} /$ day. Most of the hazardous wastes are surgical wastes. The rate of waste generation is $0.072 \mathrm{~kg} /$ patient/day. The percentage amount of sharp waste is $15 \%$, pathological waste is $13 \%$, pharmaceutical waste is $25 \%$ and general waste is $47 \%$ (Figure 7 ).

\section{Graphical Representation}

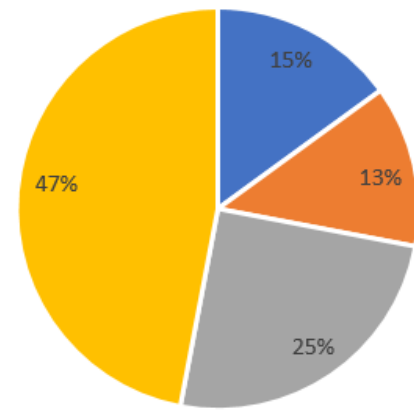

- Sharps

- Pathological

- Pharmaceutical

" General

Figure 7: Percentage of clinical Waste at Rajshahi Royal Hospital.

\section{Percentage of clinical waste Zamzam Islami Hospital}

Another popular private hospital in Rajshahi city is Zamzam Islami Hospital. The hospital has 30 beds capacity for resident patients and provides outdoor facilities for about 200 patients daily. Hospital having facilities are pathology, radiology and imaging, microbiology, surgery, pharmacology, gynecology and so on).

Total amount of waste generated is $18.618 \mathrm{~kg} /$ day (average) on which hazardous waste is $4.61 \mathrm{~kg} /$ day. Most of the hazardous wastes are surgical wastes. The rate of waste generation is $0.08 \mathrm{~kg} /$ patient/ day. The percentage amount of sharp waste is $12 \%$, pathological waste is $7 \%$, pharmaceutical waste is $21 \%$ and general waste is $60 \%$ (Figure 8).

\section{Graphical Representation}

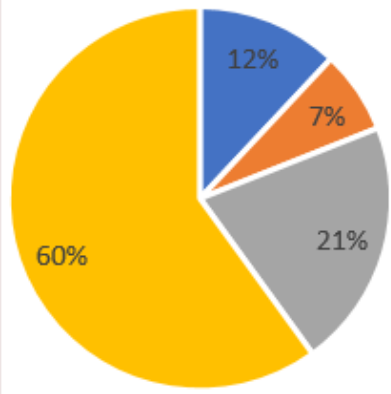

- Sharps

- Pathological

- Pharmaceutical

w General
Figure 8: Percentage of clinical Waste at Zamzam Islami Hospital.

\section{Percentage of clinical waste at Popular Diagnostic Centre}

Popular Diagnostic Centre is one of the largest diagnostic centres in Rajshahi city having latest technology for pathogenic test, blood test, urine test etc. The hospital has no bed capacity for resident patients but provides outdoor facilities for about 700 patients daily.

Total amount of waste generated is $39.83 \mathrm{~kg} /$ day (average) on which hazardous waste is $9.2 \mathrm{~kg} /$ day. The rate of waste generation is $0.057 \mathrm{~kg} / \mathrm{patient} /$ day. The percentage amount of sharp waste is $16 \%$, pathological waste is $8 \%$, and pharmaceutical waste is $18 \%$ and general waste is $58 \%$ (Figure 9).

\section{Graphical Representation}

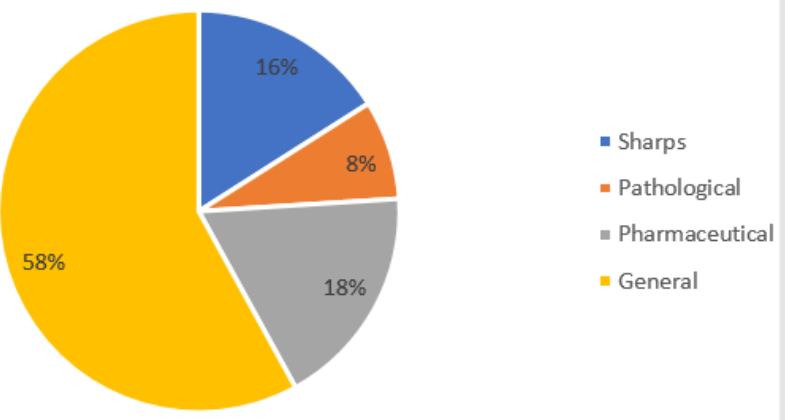

Figure 9: Percentage of clinical waste at Popular Diagnostic Centre.

\section{Analysis of Clinical Waste Management in Selected Hospitals}

\section{Waste segregation}

The key to minimization and effective management of healthcare waste is segregation and identification of waste. Appropriate 
handling, treatment and disposal of waste by type reduce costs and do much to protect public health. It was observed that there were no segregation systems for infectious and non-infectious wastes at the site of production almost in all the Health Care Establishments. There was little systematic collection in the surveyed Health Care Establishments. They keep hazardous wastes such as syringes, gauges, cotton, blades, knives and infectious substances in red and yellow colored containers and non-hazardous wastes such as saline bags, plastic bottles, paper, kitchen garbage etc. in the green and black colored containers (Figure 10).

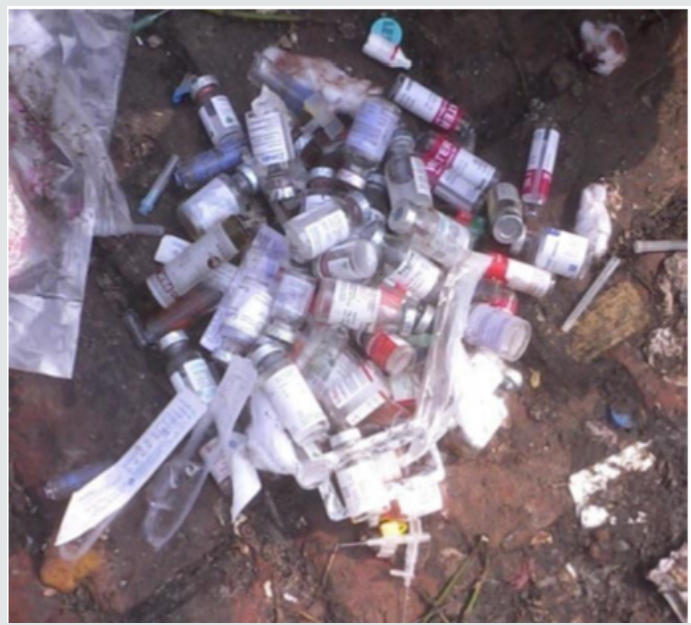

Figure 10: Segregation of waste.

\section{On-site handling and Temporary storage}

This is an important element in the overall solid waste management system because it can have significant effects on public health and on subsequent functional elements on the systems. Onsite handling refers to the activities associated with the handling of solid wastes until they are placed on containers for storage before collection. The place/storage area where medical wastes were kept before transporting to the incinerator or final disposing site was termed as temporary waste storage (Figure 11).

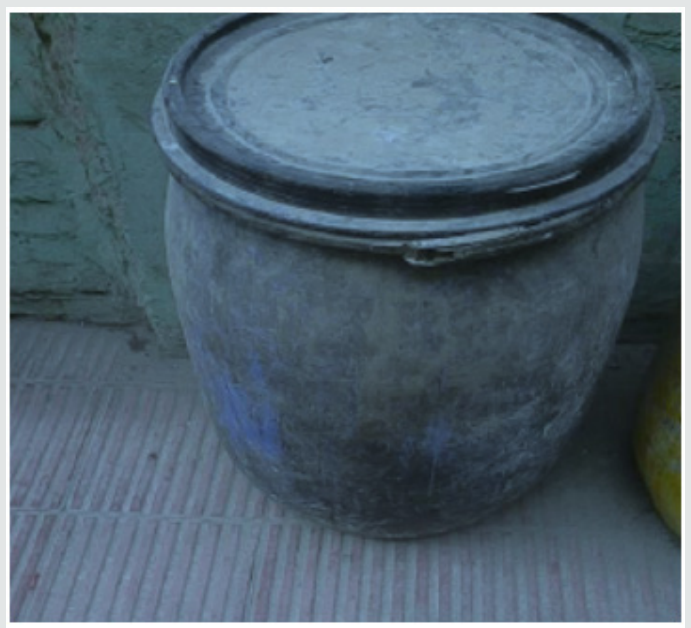

Figure 11: Temporary waste storage containers.

\section{Off-site transportation}

Clinical waste should normally be collected everyday due to its hazardous nature. The Rajshahi City Corporation has the responsibility for off-site transportation of the waste for final disposal or dumping. Rajshahi City Corporation authorities provide a van for collecting wastes from different Health Care Establishments. Every early morning, they collect wastes from Health Care Establishments and these collected wastes were transported to either the incinerator which is located at Rajshahi Medical College Hospital premises or Nowdapara Bhagar for dumping (Figure 12).

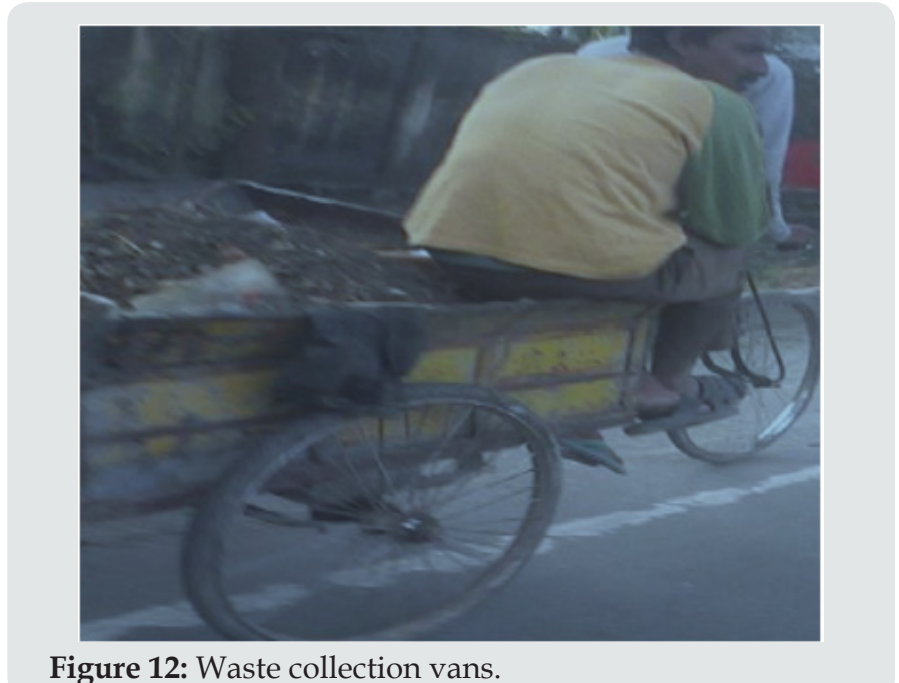

\section{Final disposal}

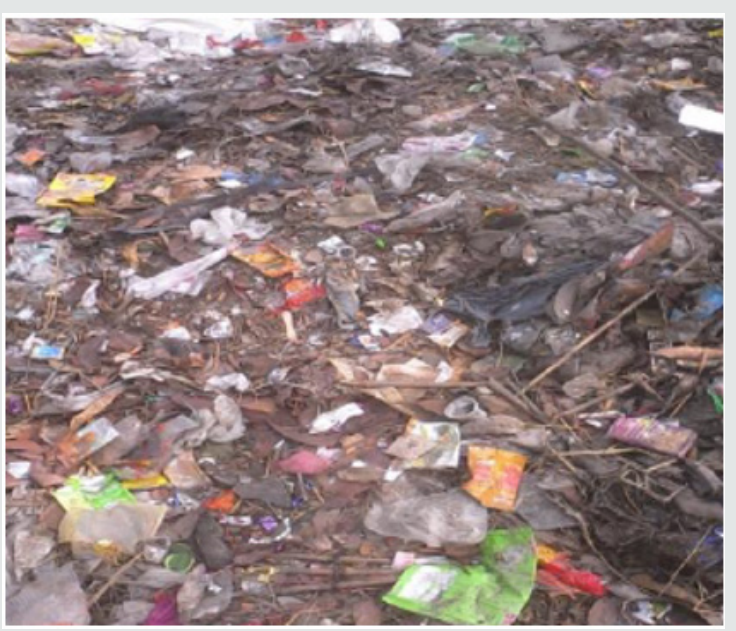

Figure 13: Final disposal site.

The final disposing site in Rajshahi City Corporation was situated at Nawdapara which was locally called "Nawdapara Bhagar". Medical wastes were collected everyday by rajshahi city corporation van due to its hazardous nature. Every early morning, the collected wastes are finally dumped by city corporation registered cleaners to this "Bhagar". It was found from the survey 
that there was no consideration of distinguishing infectious waste with non-infectious waste when dumping. So, it may cause pollution to the environment as well as health hazard to people (Figure 13).

\section{Discussion}

From the field investigation, we observed that some Health Care Establishments are more systematic for color coding and segregation. Others follow color coding system and segregation but comparatively less than WHO standards. The hospital staffs from selected hospitals have awareness about hospital waste management practices but they need more training to do this in systematic way. Hazardous hospital waste is the serious problem for the Rajshahi city. Therefore, the efficient hospital waste management practice is essentially needed for all hospital in the Rajshahi city. The authorized person from hospital and solid waste management organization should try for possible waste reduction way from the hospitals. All the selected hospitals should follow the WHO guideline in the case of color coding. Temporary storage is kept separate for the general waste and hazardous waste.

The workers from all hospitals should carry the waste with trolley but at present they carry and transport with their own hand. Moreover, the workers have no protective clothes during the hospital waste handling. Clinical waste management in the Rajshahi is needed to provide training for hospital staff.

Rajshahi City Corporation manages treatment and disposal of hospital waste in Rajshahi City. They use incineration method for treatment. They cannot follow WHO guideline properly. General waste from hospital is sent to the open dumping site. Therefore, all of the hospital of Rajshahi City should try to improve their waste management practice.

\section{Conclusion}

The collection, storage and disposal of clinical wastes are of growing environmental problem in Bangladesh. Clinical wastes pose a significant impact on health and the environment. There is not enough information on clinical waste management technologies and impacts in developing countries. All selected clinics and diagnostic centers are joined with Rajshahi City Corporation for waste disposal and treatment. The collected field data showed that all the Health Care Establishment generate pathological wastes, used syringes, broken glass and bottles, textile stained with blood and papers. The level of awareness on clinical waste is very high, but they are not able to manage the waste systematically since there are lacking of systems, rules and regulations and financial support.
The Rajshahi City Corporation also has some limitation for proper clinical waste management. Actually, when they collect these wastes, they used to collect hazardous and non-hazardous waste in a single van and then the wastes are mixed. Also, they dispose the all clinical wastes in the same area. So there remains a great chance of environmental pollution. Hence, we should raise the level of awareness and should follow the proper rules and regulation for clinical waste management.

\section{References}

1. WHO (1999) Guidelines for safe disposal of unwanted pharmaceuticals in and after emergencies. Essential Drugs and Other Medicines Department, World Health Organization, Avenue Appia 20, CH-1211 Geneva 27, Switzerland.

2. Tamplin SA, Davidson D, Powis B, O Leary Z (2005) Issues and options for the safe destruction and disposal of used injection materials. Waste Manag 25(6): 655-665.

3. Blen Kharn JI (2006) Clinical Waste Management. Blenkharn Environmental Ealing, London, UK, England.

4. Da Silva CE, Mukelh Y (2001) The management of Clinical Waste and its impact on environment.

5. Mato, Kaseva (1999) Critical review of industrial and medical waste practices in Dar es Salaam City. 25(3-4): 271-287.

6. Aruna Biswas (2011) Medical Waste Management in the Tertiary Hospitals of Bangladesh, an Empirical Enquiry. ASA University Review, Bangladesh, 5(2).

7. Ahmed A (2000) Hospital Waste Management: Problems and strategic Solutions, Dhaka, Bangladesh.

8. Akter (1997) Medical Waste Disposal at BRAC Health Centre.

9. Askarian M, Vakili M, Kabir G (2004) Results of a hospital waste survey in private hospitals in Fars Province, Iran. Waste Manag 24(4): 347-352.

10. Ecoaccess (2004) Information sheet on waste management, determining whether waste is clinical waste.

11. JICA (2004) Clean Dhaka Master Plan. Progress report, JICA, Dhaka, Bangladesh.

12. Nasima Akter Medical Waste Management in the tertiary hospitals of Bangladesh: An Emperical Enquiry. Medical Waste Management: A Review.

13. Nasima Akter (1999) Clinical Solid Waste Management practices and its impact on human health and environment -A review.

14. Neema SK, Ganeshprasad KS (2002) Plasma pyrolysis of medical waste. Current Science 83(3): 271-278.

15. UNEP (2003) Technical Guidelines on the environmentally sound management of Bio-medical and Healthcare wastes (Y1; Y3), Ghatelaine UNEP.

16. Mia MY, Ali MA, Rahman MA, Naznin L, Hossain MU (2012) Waste Management in Tangail Municipality. J Environment Sci \& Natural Resources 5(1):121-127.

17. WHO (2000) Wastes from healthcare activities. WHO information, Fact Sheet No 253, October 2000. 


\section{(c) $(9$ \\ This work is licensed under Creative Commons Attribution 4.0 License}

To Submit Your Article Click Here: Submit Article

DOI: 10.32474 /TCEIA.2019.03.000161

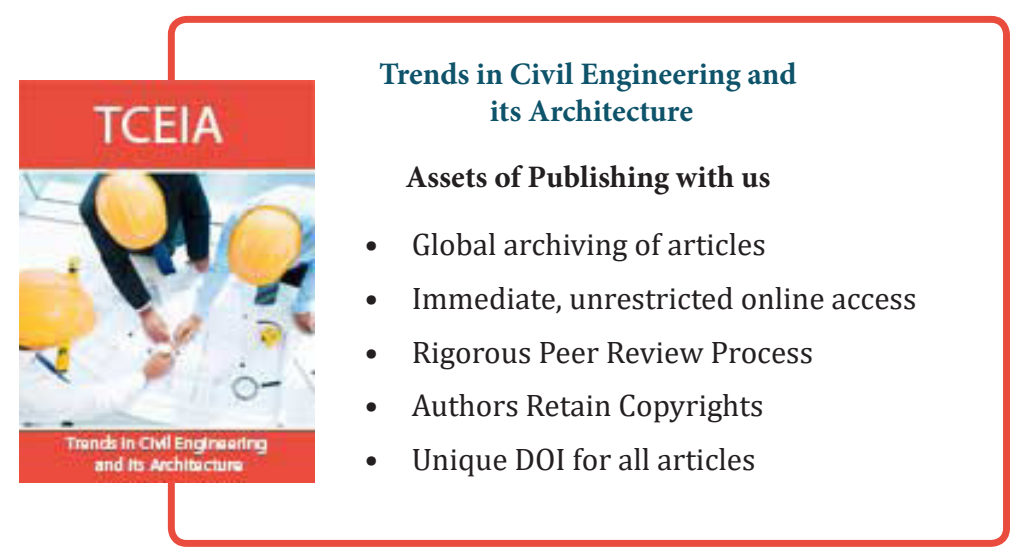

